\title{
Polpa de caju em rações para frangos de corte na fase final: desempenho e características de carcaça
}

\author{
Lidiana de Siqueira Nunes Ramos ${ }^{1}$, João Batista Lopes ${ }^{2}$, Agustinho Valente de Figueirêdo², Almir \\ Chalegre de Freitas ${ }^{3}$, Leonardo Atta Farias ${ }^{4}$, Lucilene da Silva Santos ${ }^{5}$, Hunaldo Oliveira Silva ${ }^{6}$ \\ ${ }^{1}$ Mestre em Ciência Animal pela Universidade Federal do Piauí - UFPI - Rua Deputado João Carvalho, 4886 - Morada do Sol. Teresina - PI. \\ 2 Universidade Federal do Piauí - Campus da Socopo - Teresina - PI \\ ${ }^{3}$ Doutor em Zootecnia, Bolsista DCR - CNPq/FAPEPI/UFPI. \\ ${ }^{4}$ Mestrando do Curso de Ciência Animal da Universidade Federal do Piauí - UFPI. \\ ${ }^{5}$ Aluna do Curso de Graduação em Medicina Veterinária - UFPI. \\ ${ }^{6}$ Escola Agrotécnica Federal de São Cristóvão - Sergipe
}

RESUMO - A pesquisa foi desenvolvida com os objetivos de avaliar o desempenho e as características de carcaça de frangos de corte alimentados com dietas contendo diferentes níveis de polpa de caju desidratada e analisar a viabilidade econômica desse sistema de produção. Foram utilizados 320 frangos com 22 dias de idade, da linhagem Ross, de ambos os sexos, distribuídos em delineamento em blocos casualisados, com quatro tratamentos - níveis de inclusão $(0,5,10$ e 15\%) de polpa de caju desidratada (PCD) - e cinco repetições com 16 aves. Aos 42 dias de idade, foram selecionadas, por peso e sexo, quatro aves (dois machos e duas fêmeas) por unidade experimental, as quais foram abatidas para avaliação do rendimento de carcaça e de seus cortes. A inclusão de até $15 \%$ de polpa de caju desidratada em rações para a fase de crescimento não influenciou o consumo, o ganho de peso e as principais características de carcaça dos frangos de corte. A conversão alimentar piorou e a viabilidade econômica (renda bruta e margem bruta média) foi menor com o incremento da polpa de caju desidratada nas rações. O uso de polpa de caju desidratada para frangos de corte depende do preço da polpa em relação ao preço do ingrediente convencional (milho) e do óleo vegetal utilizado na formulação da dieta.

Palavras-chave: caju, características de carcaça, desempenho, frango de corte

\section{Dietary dehydrated cashew pulp for finishing broilers: performance and characteristics carcass}

\begin{abstract}
This research was developed to evaluate the performance, carcass characteristic and economical viability of broilers fed diets with increasing levels of dehydrated cashew pulp. Three hundred and sixty Ross breed broilers of both sexes averaging 22 days old were allotted to randomized blocks design with four treatments, constituted of dehydrated cashew pulp levels $(0,5,10$, and 15\%) and five replications. At 42 days old, four birds (two males and two females) were slaughtered by weight and sex per experimental unit to evaluate the main carcass characteristics. The $15 \%$ level of dehydrated cashew pulp in the growing diets did not affect feed intake, weight gain and main carcass characteristics of broiler. No effects of increasing levels on feed gain ratio and economical analyses (gross revenue and average gross margin) were noticed. The use of dehydrated cashew pulp in the broiler diets depends on the diet prices.
\end{abstract}

Key Words: broiler, cashew, characteristics cascass, performance

\section{Introdução}

O frango de corte, entre os animais produtores de alimentos para o homem, destaca-se por transformar produtos de origem vegetal em proteína de alta qualidade. Entretanto, no sistema de produção de aves, o gasto com a alimentação corresponde a aproximadamente $80 \%$ do custo total. Estas constatações têm levado produtores e técnicos à buscar medidas alternativas que reduzam os custos, pois as oscilações ocorridas nos preços dos principais insumos utilizados na nutrição desses animais (milho e soja) têm levado o setor avícola a vivenciar fortes crises econômicas. A alimentação, por ser um componente importante na planilha dos custos de produção, precisa se adequar à evolução genética das aves, respeitando as peculiaridades regionais, o meio ambiente e os tipos de alimentos produzidos, que podem afetar a relação custo/benefício da atividade.

Os grandes avanços na genética de frangos de corte devem estar em harmonia com aqueles nas áreas de manejo, nutrição, sanidade e ambiência.

A produção de grãos no Nordeste do Brasil, especialmente de milho, é insuficiente para atender à demanda por 
alimentos dos rebanhos, sobretudo de aves e suínos, em razão da baixa produtividade da lavoura na região. Os custos das rações elaboradas em granjas avícolas são elevados, em virtude da necessidade de importar de outras regiões do país e, até do exterior, insumos básicos, como o milho, utilizados na formulação das rações para frango de corte.

Nesse contexto, o aproveitamento de matérias-primas de vegetais regionalmente adaptados é fundamental para a melhora da oferta de alimentos que possam substituir parcial ou totalmente o milho na composição das rações animais. Entretanto, tem-se observado grande desperdício de subprodutos resultantes do beneficiamento de frutos tropicais com excelente potencial para utilização na alimentação animal, como é o caso do caju.

A proposta de se estudar a inclusão da polpa de caju desidratada (PCD) em rações para frangos de corte visa à redução dos custos de produção no setor avícola da Região Nordeste, pois trata-se de um subproduto disponível na entressafra do milho e que normalmente é desperdiçado. De acordo com o IBGE (2004), o estado do Piauí se destaca como o terceiro maior produtor de caju do Brasil, atualmente com 170 mil ha cultivados, dos quais aproximadamente 154 mil estão em produção. Em 2003, a produção foi de 26 mil toneladas de castanha, inferior apenas à dos estados do Ceará e Rio Grande do Norte (107 e 30 mil toneladas, respectivamente).

Esses dados merecem atenção dos criadores e do meio técnico-científico, pois o fruto do cajueiro é constituído da castanha (10\%) e do pseudofruto (90\%), observando-se, na prática, que grande parte do pseudofruto é deixada no campo, após a retirada da castanha. Esse produto poderá ser colhido, processado para a produção de suco, doces e cajuínas e o subproduto servir como alternativa para alimentação animal, posto que, na composição da matéria seca da PCD, existem mais de $30 \%$ de açúcares que podem ser metabolizados como fonte de energia para reações de biossíntese (Holanda et al., 1998; Emparn, 2002).

A utilização da PCD já foi testada por vários autores, como Gadelha et al. (1978), que substituíram o milho pela polpa de caju desidratada em rações para frangos de corte e verificaram menor ganho de peso e piora da conversão alimentar como resultado do aumento dos níveis de polpa de caju nas dietas. Araújo (1987), ao substituir o milho pela PCD em rações para frangos de corte, observou que o crescente teor de tanino nas rações provocou aumento no consumo de ração, reduziu o ganho de peso e piorou a conversão alimentar das aves. Por sua vez, Silva Filha et al. (2004), constataram que a inclusão de até $24 \%$ de polpa de caju desidratada em dietas para frangos de corte não alterou o ganho de peso, mas piorou a conversão alimentar das aves.
Costa (1988) e Tavares (1993) ressaltaram que, ao projetar custos de formulações de dietas para frangos de corte, é necessário considerar o custo unitário de cada ingrediente e valorizá-lo por seu conteúdo em nutrientes nobres. A utilização de fontes alimentares alternativas em rações para frangos de corte visando minimizar o custo por unidade de ganho de peso, utilizando-se rações nutricionalmente balanceadas a um custo mínimo, permite abordar em pesquisas não apenas os parâmetros zootécnicos, mas também os econômicos.

Objetivou-se com este estudo avaliar o desempenho (ganho de peso, consumo de ração e conversão alimentar), as características de carcaça de frangos de corte alimentados com dietas contendo diferentes níveis de polpa de caju desidratada e analisar a viabilidade econômica desse sistema de produção.

\section{Material e Métodos}

A pesquisa foi realizada no Setor de Avicultura do Departamento de Zootecnia do Centro de Ciências Agrárias da Universidade Federal do Piauí (DZO-CCA-UFPI), em Teresina, Piauí, no período de 30 de março a 10 de maio de 2004. Foram utilizados pintinhos da linhagem Ross de 1 a 21 dias de idade, alojados em galpão convencional e alimentados com ração inicial à base de milho, farelo de soja, óleo de soja, fosfato bicálcico, calcário, sal comum, lisina HCL, DL-metionina e premix vitamínico e mineral, formulada para atender às exigências nutricionais, segundo Rostagno et al. (2000).

Os pintinhos receberam ração e a água ad libitum e, nos dez primeiros dias de idade, foram submetidos a um sistema de aquecimento com lâmpadas incandescentes de 100 watts, e a um programa de vacinação contra as doenças de newcastle e gumboro (aos oito dias de idade), via ocular, com reforço da vacina de gumboro aos 16 dias de idade, também por aplicação ocular.

Aos 21 dias de idade, foram selecionados do lote inicial, de forma individual e por peso, 320 frangos (160 machos e 160 fêmeas). Na fase experimental ( 22 a 42 dias), as aves foram distribuídas em 20 boxes com $3,00 \mathrm{~m}^{2}$, alojados em um galpão de alvenaria, coberto com telhas de barro e piso cimentado, contendo cortinas para controle da temperatura e de correntes de ar. O galpão era dotado de bebedouros pendulares e comedouros tubulares e as divisórias entre os boxes eram de tela de arame liso. Cada boxe alojou 16 aves (oito machos e oito fêmeas) e possuía cama de palha de arroz de aproximadamente de $5 \mathrm{~cm}$ de espessura.

O programa de luz adotado foi contínuo durante as 24 horas do dia, sendo das 6 h30 às 17 h30 iluminação natural, 
e o restante do dia com luz artificial, utilizando-se lâmpadas fluorescentes de 75 watts. O monitoramento da temperatura e da umidade do galpão foi feito, respectivamente, por meio de termômetro e higrômetro colocados à altura intermediária em relação aos boxes. As leituras do termômetro e higrômetro foram realizadas diariamente duas vezes ao dia (9 e $15 \mathrm{~h})$, observando-se médias de $29,2 \pm 1,31^{\circ} \mathrm{C}$ e $59,7 \pm 11,52 \%$, respectivamente. No período em que a temperatura ultrapassava a zona de termoneutralidade, eram acionados ventiladores elétricos para diminuição do estresse por calor.

As dietas experimentais (Tabela 1), isonutritivas, foram formuladas à base de milho e farelo de soja, com diferentes níveis de $\mathrm{PCD}(0,5,10$ e $15 \%)$, para atender às exigências nutricionais, segundo Rostagno et al. (2000). As formulações das dietas foram feitas em planilhas pelo programa excel. O valor da energia metabolizável e dos nutrientes da PCD utilizada para a formulação das rações está de acordo com os descritos pela Embrapa (1991) e por Araújo (1987), respectivamente.

A PCD utilizada no experimento foi proveniente de uma fábrica de sucos e doces situada em Ipiranga, região sul do estado do Piauí. O processo de desidratação adotado pela empresa fornecedora consiste na exposição do bagaço do caju ao sol em área cimentada durante três a quatro dias, fazendo-se a remoção periódica para uniformizar a secagem e evitar fermentação do material. Na época da elaboração das rações, foi determinada em laboratório a composição química e bromatológica da $\mathrm{PCD}$, que apresentou $88,70 \%$ de MS, $4.320 \mathrm{kcal} / \mathrm{kg}$ de EB, $4,15 \%$ de EE, $14,00 \%$ de PB, $12,07 \%$ de $\mathrm{FB}, 0,45 \%$ de $\mathrm{Ca}, 0,30 \%$ de $\mathrm{P}$ e $1,8 \%$ de tanino.

Foram analisados o consumo de ração (CR), o ganho de peso (GP) e a conversão alimentar (CA) no período de 22 a 42 dias de idade, além das características de carcaça e da viabilidade econômica no final do experimento.

O ganho de peso foi determinado pela diferença entre o peso das aves no início e no fim do período experimental. O consumo de ração foi calculado também por diferença entre a quantidade de ração fornecida e as sobras. A partir dos dados de consumo de ração/ganho de peso, foi calculada a conversão alimentar dos animais.

Ao final do experimento ( 42 dias de idade), as aves foram pesadas após jejum alimentar de oito horas, sendo selecionadas para o abate (por peso médio e sexo) quatro aves (dois machos e duas fêmeas) por unidade experimental. Após o sangramento e a depenação, as aves foram evisceradas e as carcaças (excluindo cabeça e pés) foram pesadas.

O rendimento de carcaça foi determinado pela relação entre o peso da carcaça eviscerada e o peso vivo das aves na plataforma de abate. Também foi determinado o rendimento percentual dos cortes e da gordura abdominal (tecido
Tabela 1- Composição das rações finais de acordo com os níveis de polpa de caju desidratada

Table 1 - Ingredient composition according to increasing levels of dehydrated cashew pulp

\begin{tabular}{|c|c|c|c|c|c|}
\hline \multirow[t]{2}{*}{$\begin{array}{l}\text { Ingrediente } \\
\text { Ingredient }\end{array}$} & \multirow[t]{2}{*}{$\begin{array}{l}\text { Unidade } \\
\text { Unit }\end{array}$} & \multicolumn{4}{|c|}{$\begin{array}{c}\text { Nível de inclusão da } \\
\text { polpa de caju desidratada (\%) } \\
\text { Inclusion levels of dehydrated cashew pulp }\end{array}$} \\
\hline & & 0 & 5 & 10 & 15 \\
\hline $\begin{array}{l}\text { Milho } \\
\text { Corn }\end{array}$ & $\mathrm{kg}$ & 67,17 & 60,74 & 54,34 & 47,76 \\
\hline $\begin{array}{l}\text { Farelo de soja } \\
\text { Soybean meal }\end{array}$ & $\mathrm{kg}$ & 25,20 & 24,90 & 24,55 & 24,30 \\
\hline $\begin{array}{l}\text { Polpa de caju } \\
\text { desidratada } \\
\text { Dehydrated cashew pulp }\end{array}$ & $\mathrm{kg}$ & 0,00 & 5,00 & 10,00 & 15,00 \\
\hline $\begin{array}{l}\text { Óleo de soja } \\
\text { Soybean oil }\end{array}$ & $\mathrm{kg}$ & 3,56 & 5,30 & 7,06 & 8,85 \\
\hline $\begin{array}{l}\text { Fosfato bicálcico } \\
\text { Dicalcium phosphate }\end{array}$ & $\mathrm{kg}$ & 1,70 & 1,70 & 1,70 & 1,70 \\
\hline $\begin{array}{l}\text { Sal } \\
\text { Salt }\end{array}$ & $\mathrm{kg}$ & 0,42 & 0,42 & 0,42 & 0,42 \\
\hline $\begin{array}{l}\text { Calcário } \\
\text { Limestone }\end{array}$ & $\mathrm{kg}$ & 1,00 & 1,00 & 1,00 & 1,00 \\
\hline $\begin{array}{l}\text { DL-metionina } \\
\text { DL-methionine }\end{array}$ & $\mathrm{kg}$ & 0,16 & 0,16 & 0,16 & 0,16 \\
\hline $\begin{array}{l}\text { Lisina-HCL } \\
\text { Lysine } \mathrm{HCl}\end{array}$ & $\mathrm{kg}$ & 0,29 & 0,28 & 0,27 & 0,26 \\
\hline Premix vitamínico & $\mathrm{kg}$ & 0,50 & 0,50 & 0,50 & 0,50 \\
\hline
\end{tabular}

mineral

Mineral and vitamin mix

Total

$100,00 \quad 100,00 \quad 100,00 \quad 100,00$

Valor calculado ${ }^{2}$

Calculated value ${ }^{2}$

\begin{tabular}{|c|c|c|c|c|c|}
\hline $\begin{array}{l}\text { EM } \\
\text { Metabolizable energy }\end{array}$ & $\mathrm{kcal} / \mathrm{kg}$ & 3100 & 3100 & 3100 & 3100 \\
\hline Proteína bruta & $(\%)$ & 19,30 & 19,30 & 19,30 & 19,30 \\
\hline $\begin{array}{l}\text { Crude protein } \\
\text { Cálcio }\end{array}$ & $(\%)$ & 0,87 & 0,87 & 0,87 & 0,87 \\
\hline $\begin{array}{l}\text { Calcium } \\
\text { Fósforo disponível } \\
\text { Available phosphorus }\end{array}$ & $(\%)$ & 0,41 & 0,41 & 0,41 & 0,41 \\
\hline $\begin{array}{l}\text { Fibra bruta } \\
\text { Crude fiber }\end{array}$ & $(\%)$ & 2,89 & 3,34 & 3,79 & 4,25 \\
\hline $\begin{array}{l}\text { Metionina } \\
\text { Methionine }\end{array}$ & $(\%)$ & 0,45 & 0,45 & 0,45 & 0,45 \\
\hline $\begin{array}{l}\text { Lisina-HCL } \\
\text { Lysine }\end{array}$ & $(\%)$ & 1,16 & 1,16 & 1,16 & 1,16 \\
\hline $\operatorname{Tanino}^{3}$ & $(\%)$ & 0,00 & 0,20 & 0,42 & 0,60 \\
\hline
\end{tabular}

Tannin

${ }^{1}$ Conteúdo/kg (Content/kg): Vit. A - 198.000,00UI; Vit. D3 - 49.500,00 UI; Vit - E 390,00 Ul; Vit. $B_{2}-160,00$ mg; Vit. $B_{5} 880,00$ mg; Vit. $B_{3}-240,00$ mg Vit. $\mathrm{B}_{12} 400 \mathrm{mcg}$; cloreto de colina (Choline chloride) - $80 \mathrm{~g}$; metionina (methionine)-30,00 g; promotor de crescimento (growth promoter) $-700,00 \mathrm{mg}$ antioxidante (antioxidant) - $200 \mathrm{mg}$; monensina sódica (sodium monensin) 2.000,00 mg; Ca - 115,00 mg; Cu - 2.970,00 mg; F (max.) - 645,00 mg; $\mathrm{P}-65,00 \mathrm{~g} ; \mathrm{I}-40,00 \mathrm{mg} ; \mathrm{Mn}-2.200,00 \mathrm{mg}$; Se - 4,00 mg; Na - 23,00 g; Zn - 1.760,00.

2 Valores calculados com base nos dados descritos por Araújo (1987), pela Embrapa (1991) e por Rostagno et al. (2000)

3 Tanino da PCD.

${ }^{2}$ Calculated values by Araújo (1987), Embrapa (1991) e Rostagno et al. (2000).

${ }^{3}$ Tanin of $P C D$

adiposo em torno da bursa de Fabricius, do proventrículo, da moela e da cloaca) em relação ao peso da carcaça eviscerada.

Os cortes de asas, entreasas, peito, coxas, sobrecoxas, dorso e pescoço foram pesados em balança digital e seus 
rendimentos calculados em relação ao peso da carcaça eviscerada. Foram avaliados os pesos relativos (\%) das carcaças, dos cortes supracitados, da gordura abdominal e dos órgãos comestíveis (coração, fígado e moela) utilizando-se fórmulas descritas por Freitas (1999).

Para análise do desempenho, os frangos foram distribuídos em delineamento em blocos ao acaso, com quatro tratamentos, cinco repetições e 16 aves por unidade experimental (boxe). Os resultados foram submetidos à análise da variância e ao teste de regressão, por meio do STATISTICAL ANALYSIS SYSTEM-SAS(1986).

O estudo da viabilidade econômica da inclusão de polpa de caju desidratada na ração foi realizado conforme relatado por Freitas (1999), considerando-se as seguintes variáveis primárias: consumo médio de ração (CMR, $\mathrm{kg}$ ), custo da ração (CR, kg), ganho de peso médio (GPM, kg), peso vivo médio (PVM, kg) e preço do frango vivo (PFV, kg). Com base nos valores observados para essas variáveis primárias, foram obtidos os seguintes indicadores econômicos: custo médio de alimentação $(\mathrm{CMA})=\mathrm{CMR} \times \mathrm{CR}$, relação $\mathrm{CMA} / \mathrm{GPM}$, renda bruta média $(\mathrm{RBM})=\mathrm{PVM} \times \mathrm{PFV}$, margem bruta média $(\mathrm{MBM})=\mathrm{RBM}-\mathrm{CMA}$.

Calculou-se a margem bruta (MB), considerando-se: $\mathrm{MB}=(\mathrm{kg}$ frango produzido $\mathrm{x}$ preço de venda do frango $)-$ (preço da ração x ração consumida), envolvendo os preços dos ingredientes constantes nas rações.

\section{Resultados e Discussão}

Os resultados de desempenho (ganho de peso, consumo de ração e conversão alimentar) no período de 22 a 42 dias de idade, de acordo com os níveis de PCD são na Tabela 2.

Os níveis de PCD não interferiram no consumo de ração (g) e no ganho de peso $(\mathrm{g})(\mathrm{P}>0,05)$, indicando que a PCD pode ser incluída em rações para frango de corte em crescimento até o nível de $15 \%$, sem comprometer estas características de desempenho. Entretanto, os níveis de inclusão de PCD interferiram significativamente na conversãoalimentar, resultando em efeito linear positivo $(\mathrm{P}<0,05)$, representado pela equação de regressão: $\mathrm{Y}=2,2+0,0158 \mathrm{X}\left(\mathrm{R}^{2}=0,2375\right)$. $\mathrm{A}$ medida que o nível da PCD na dieta aumentou, a conversão alimentar piorou, indicando que esse ingrediente afeta essa variável. De acordo com a equação de regressão, para cada $1 \%$ de inclusão de PCD na ração houve aumento de 0,0158 unidades na conversão alimentar, comprovado pelo efeito linear crescente demonstrado na Figura 1.

Como as rações eram isoenergéticas, o consumo provavelmente não foi afetado pelos tratamentos, o que está de acordo com os dados citados por Beterchini et al. (1991) e Barbosa (2003). Estes autores afirmam que os animais consomem alimentos buscando prioritariamente satisfazer às necessidades energéticas, desde que o trato digestivo não se constitua limitação. Entretanto, Hall et al. (1978) observaram redução no consumo à medida que aumentaram o teor de tanino na ração, o que não foi observado nessa pesquisa, mesmo com a ração contendo o maior nível de PCD (15\%) e de tanino $(0,6 \%)$.

Os resultados desta pesquisa corroboram os obtidos por Silva Filha et al. (2004), que, ao incluirem até $24 \%$ pseudofruto desidratado do caju em dietas para frangos de corte, também constataram que o ganho de peso não foi influenciado.

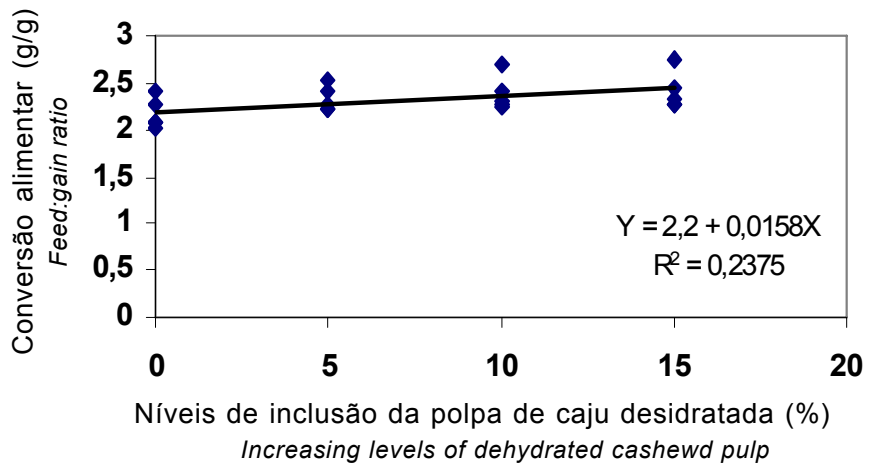

Figura 1 - Efeito dos níveis de polpa de caju desidratada na ração sobre a conversão alimentar de frangos de corte no período de 22 a 42 dias de idade.

Figure 1 - Feed:gain ratio of broiler from 22 to 42 day old as affected by increasing levels of dehydrated cashewd pulp.

Tabela 2 - Desempenho de frangos de corte alimentados com dietas contendo polpa de caju desidratada

Table 2 - $\quad$ Performance of broiler fed diets with increasing levels of dehydrate cashewd pulp

\begin{tabular}{lcccc}
\hline Variável & \multicolumn{3}{c}{$\begin{array}{c}\text { Nível de inclusão da polpa de caju desidratada (\%) } \\
\text { Increasing level of cashew dehydrated pulp (\%) }\end{array}$} \\
\cline { 2 - 4 } & 0 & 5 & 10 & 15 \\
\hline Consumo de ração (kg) (Feed intake) & 3,213 & 3,348 & 3,468 & 3,424 \\
Ganho de peso (kg) (Weight gain) & 1,485 & 1,444 & 1,460 & 1,423 \\
Conversão alimentar1 (g/g) (Feed:gain ratio) & 2,16 & 2,32 & 2,38 & 4,26 \\
\hline
\end{tabular}

${ }^{1}$ Efeito linear $(P<0,05)$

${ }^{1}$ Linear effect $(P<0.05)$. 
Entretanto, Gadelha et al. (1978), substituíram o milho pela polpa desidratada de caju em rações para frangos de corte e verificaram menor ganho de peso.

Gadelha et al. (1978) e Araújo (1987) constataram piora na conversão alimentar com o aumento dos níveis de PCD nas dietas, provavelmente em razão do alto teor de tanino $(1 \%)$ e de fibra bruta do pseudofruto do caju presente na ração. Segundo Durigan (1994), o tanino é um composto fenólico com capacidade de combinar proteínas e carboidratos para formar complexos estáveis. Desse modo, os altos teores de tanino na ração diminuem o aproveitamento energético da ração e aumentam o consumo. Apesar do nível de teor de tanino nas rações ter sido inferior a $1 \%$, também foram encontrados resultados similares. Contudo, Silva Filha et al. (2004) registraram melhora na conversão alimentar ao incluírem a PCD em até $24 \%$ nas dietas de frangos de corte.

Outro fator que possivelmente influenciou a conversão alimentar das aves foi o aumento crescente no teor de FB $(2,89 ; 3,34 ; 3,79$ e $4,25 \%$, respectivamente, com a inclusão de $0,5,10$ e $15 \%$ de PCD na ração). De acordo com Scott et al. (1976), o alto teor de fibra bruta pode interferir na qualidade da ração produzida e na disponibilidade dos nutrientes e reduzir o desempenho das aves.

Segundo Panigrahi (1992) e Rodríguez-Palenzuela \& Garcia (1998), o alto teor de fibra na PCD tem alta capacidade relativa de absorção de água. A fração solúvel da fibra produz efeitos negativos no desempenho das aves, associados ao aumento da viscosidade intestinal e às alterações morfológicas e fisiológicas no trato digestivo (Classen, 1996).
Philip et al. (1995) e Classen (1996) afirmam que a fração solúvel da fibra em contato com a água forma um gel que reduz o tempo de trânsito do alimento e funciona como barreira à ação hidrolítica das enzimas, pois dificulta o contato com os grânulos de amido e as moléculas protéicas e lipídicas do alimento, diminuindo o contato do bolo alimentar com as células absortivas da membrana intestinal. Esse efeito provoca redução na digestão e na absorção dos nutrientes da ração. Certamente, esses eventos reduzem a conversão alimentar das aves alimentadas com o mais alto nível de PCD nas rações, como observado neste experimento.

Os pesos relativos das características de carcaça e dos principais cortes e órgãos comestíveis dos frangos abatidos aos 42 dias de idade alimentados com rações contendo diferentes níveis de polpa de caju desidratada encontram-se na Tabela 3.

Os níveis de PCD não interferiram no peso de carcaça, asas, peito, coxas, sobrecoxas, dorso, pescoço, fígado e coração $(\mathrm{P}>0,05)$, indicando que a polpa de caju desidratada pode ser incluída em até $15 \%$ em rações para frangos de corte em crescimento, sem comprometer o valor percentual destas variáveis.

Entretanto, os níveis de inclusão de polpa de caju desidratada interferiram de forma significativa no valor percentual das entreasas, da moela e da gordura abdominal. O valor das entreasas (\%) manteve relação linear positiva $(\mathrm{P}<0,05)$, representada pela equação: $\hat{Y}=5,7649+0,0274 X\left(R^{2}=0,1175\right) . O$ valor da moela (\%) sofreu efeito linear positivo $(\mathrm{P}<0,05)$, caracterizadopela equação: $\hat{Y}=1,9044+0,0283 X\left(R^{2}=0,3702\right)$.

Tabela 3 - Percentual das principais características de carcaça de frangos aos 42 dias de idade alimentados com rações contendo diferentes níveis de polpa de caju desidratada

Table 3 - Values of main carcass characteristics of broiler slaughtered at 42 days of age as affected by increasing levels of dehydrated cashewd pulp

\begin{tabular}{|c|c|c|c|c|c|}
\hline \multirow[t]{2}{*}{$\begin{array}{l}\text { Variável } \\
\text { Variable }\end{array}$} & \multicolumn{4}{|c|}{$\begin{array}{l}\text { Nível de inclusão da polpa de caju desidratada (\%) } \\
\text { Increasing dehydrated cashew pulp levels }\end{array}$} & \multirow[t]{2}{*}{$\mathrm{CV}(\%)$} \\
\hline & 0 & 5 & 10 & 15 & \\
\hline Peso carcaça (\%) (Carcass weight) & 75,65 & 74,71 & 75,40 & 74,51 & 2,51 \\
\hline Asas (\%) (Wing) & 5,36 & 5,44 & 5,27 & 5,47 & 5,04 \\
\hline Entreasas $(\%)^{1}$ (Tulip) & 5,74 & 5,84 & 6,25 & 6,06 & 7,31 \\
\hline Peito (\%) (Breast) & 32,01 & 32,03 & 30,86 & 31,14 & 6,21 \\
\hline Coxas $(\%)$ (Legs) & 13,98 & 13,96 & 13,80 & 13,88 & 4,62 \\
\hline Sobrecoxas (\%) (Drumsticks) & 13,05 & 13,08 & 13,46 & 13,54 & 6,13 \\
\hline Dorso (\%) (Back) & 22,81 & 23,23 & 22,57 & 22,63 & 7,71 \\
\hline Pescoço (\%) (Neck) & 7,07 & 6,89 & 6,81 & 6,97 & 8,64 \\
\hline Fígado (\%) (Liver) & 2,21 & 2,22 & 2,17 & 2,10 & 11,29 \\
\hline Coração (\%) (Heart) & 0,51 & 0,56 & 0,54 & 0,54 & 9,68 \\
\hline Moela $(\%)^{1}$ (Gizzard) & 1,94 & 2,01 & 2,16 & 2,36 & 9,74 \\
\hline Gordura abdominal $(\%)(\text { Abdominal fat })^{2}$ & 2,25 & 2,66 & 2,78 & 2,05 & 22,45 \\
\hline
\end{tabular}

\footnotetext{
1 Efeito linear $(P<0,05)$.

2 Efeito quadrático $(P<0,05)$

${ }^{1}$ Linear efecct $(P<0.05)$.

2 Quadratic effect $(P<0.05)$.
} 
Porém, a gordura abdominal (\%) apresentou relação quadrática com os níveis de polpa de caju desidratada, de acordo com a equação: $\hat{Y}=2,2262+0,1603 X-0,0113 X^{2}$ $\left(\mathrm{R}^{2}=0,2497\right)$. O valor máximo médio para essa variável ocorreu no nível de 7,09\% de inclusão, indicando que, com esse valor, a ave deposita maior valor percentual de gordura abdominal, diminuindo a partir desse valor, provavelmente em razão do teor crescente de $\mathrm{FB}$, que poderá interferir na absorção dos nutrientes.

Os dados quantitativos e percentuais de carcaça comprovam que os principais cortes não foram afetados pelos níveis de PCD nas dietas, demonstrando que este ingrediente pode ser incluído nas rações, sem afetar o rendimento de carcaça, e funciona como importante alternativa para alimentação de frangos de corte.

O alto coeficiente de variação encontrado para a gordura abdominal é perfeitamente justificável pela grande variabilidade dessa característica, que sofre acentuado efeito da metodologia adotada para determinação dessa variável.

Não foi encontrada na literatura pesquisa acerca do efeito da utilização da polpa de caju desidratada como ingrediente alternativo em rações para frangos de corte sobre o rendimento de carcaça.
Os índices econômicos (custo médio de alimentação, relação custo médio de arraçoamento/ganho de peso, renda bruta e margem bruta média) obtidos são descritos na Tabela 4.

O custo médio de alimentação elevou com a inclusão de polpa de caju nas rações, de modo que aquela com $15 \%$ de PCD apresentou custo em torno de $17 \%$ superior ao da dieta controle, provavelmente em decorrência do incremento de óleo de soja na ração com o aumento dos níveis de PCD, visando manter o balanço energético. O mesmo comportamento foi observado para o custo médio de alimentação:ganho de peso, em que a ração com 15\% de PCD teve incremento de $22 \%$ em relação à ração controle. Porém, houve aumento para a renda bruta da ração controle em relação àquela com $15 \%$ de $\mathrm{PCD}$ de $1,9 \%$. A margem bruta média decresceu da dieta controle para as dietas com PCD.

\section{Conclusões}

A inclusão de até $15 \%$ de polpa de caju desidratada em rações para frangos de corte em crescimento não interfere no consumo de ração, no ganho de peso e nas principais características de carcaça das aves.

Tabela 4 - Índices econômicos obtidos com rações contendo diferentes níveis de polpa de caju desidratada

Table 4 - Economical index obtained for broiler in end phase (22 - 42 days) fed diets with increasing level of dehydrated cashew pulp

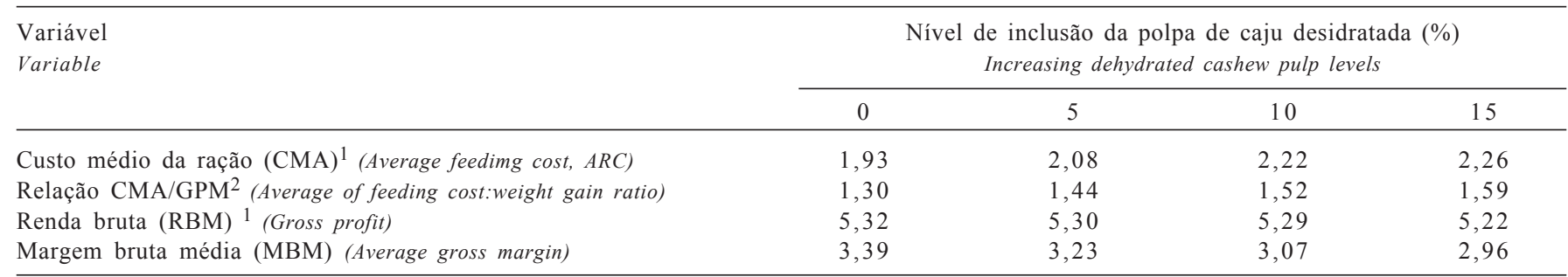

${ }_{1}^{1}$ Considerou-se o preço médio do $\mathrm{kg}$ dos ingredientes e do frango vivo, coletados em 12/11/2004.

2 GPM = Ganho de peso médio.

${ }^{1}$ It was considered the average price of ingredient $(\mathrm{kg})$ and broiler collected in 12/11/2004

2 GPM = average weight gain.

A conversão alimentar, a renda bruta média e a margem bruta média de renda decrescem com o incremento da polpa de caju desidratada em rações para frangos de corte na fase final.

O uso de polpa de caju desidratada em rações para frango de corte depende do preço desse subproduto em relação ao do ingrediente convencional (milho) e ao do óleo vegetal utilizado na formulação da ração.

\section{Literatura Citada}

ARAÚJO, Z.B. Estudo de níveis de substituição do milho pelo pseudofruto desidratado do cajueiro (Anacardium occidentale, L.) em rações para frangos de corte. Fortaleza: Universidade Federal do Ceará, 1987. 50p. Dissertação (Mestrado em Zootecnia) - Universidade Federal do Ceará, 1987.
BARBOSA, F.J.V. Desempenho, metabolismo e avaliação de carcaça de frangos de corte submetidos a diferentes níveis de energia metabolizável em Teresina, Piauí. Teresina: Universidade Federal do Piauí, 2003. 83p. Dissertação (Mestrado). Universidade Federal do Piauí, 2003.

BeterChini, A.G.; ROSTAGNO, H.S.; SilVA, M.A. et al. Efeitos da temperatura ambiente e do nível de energia da ração sobre o desempenho e a carcaça de frangos de corte. Revista Brasileira de Zootecnia, v.20, n.3, p.218228,1991

CLASSEN, H.L. Cereal grain starch and exogenous enzymes in poultry diets. Animal Feed Science Technology, n.62, p.2127, 1996.

COSTA, P.T.C. Nutrição de frangos: programas alimentares, densidade nutricional e custos de formulações. In: SEMINÁRIO DOS PRODUTORES DE PINTOS DE CORTE, 6., 1988 , Campinas. Anais... Campinas: Fundação APINCO de Ciências e Tecnologia Avícolas, 1988. p.105-114. 
DURIGAN, J.F. Fisiologia da digestão e absorção das aves: fatores antinutricionais. Campinas: Fundação APINCO de Ciências e Tecnologia Avícolas, 1994, p.127-150.

EMBRAPA, Centro Nacional de Pesquisa de Suínos e Aves. Tabela de composição química e valores energéticos de alimentos para suínos e aves. 3.ed. Concórdia: Embrapa Suínos e Aves, 1991, p.97. (Documentos, 19)

EMPRESA DE PESQUISA AGROPECUÁRIA DO RIO GRANDE DO NORTE - EMPARN. Geração e transferência de tecnologia sobre manejo e produção de ave caipira na pequena propriedade rural. Natal: 2002, p. 21 .

FREITAS, A.C. O refinazil como ingrediente de raçóes para frangos de corte. Recife: Universidade Federal Rural de Pernambuco, 1999. 89p. Dissertação (Mestrado). Universidade Federal Rural de Pernambuco, 1999

GADELHA, J.A.; SOUZA, F.M.; ARAÚJO, Z.B. et al. Estudo da substituição do milho pelo farelo do pseudo-fruto do cajueiro (Anacardium occidentale L.) In: REUNIÃO ANUAL DA SOCIEDADE BRASILEIRA DE ZOOTECNIA, 15., 1978. Belém. Anais... Belém: Sociedade Brasileira de Zootecnia, 1978. p.206.

HALL, G.A.B.; PEISCHELL, A.; STILES, D.A. et al. Níveis de ácido ânico para pintos de corte; desempenho e metabolismo da proteína bruta e energia. Revista Brasileira Zootecnia, v.7, n.1, p. $1-13,1978$.

HOLANDA, J.S.; OLIVEIRA, A.J.; FERREIRA, A.C. Enriquecimento protéico de pedúnculos de caju. Pesquisa Agropecuária Brasileira, v.33, n.5, p.787-792, 1998.

INSTITUTO BRASILEIRO DE GEOGRAFIA E ESTATISTICA IBGE. Anuário Estatístico do Brasil. Disponível em: $<$ http:/ /www.sidra.ibge.gov.br/bda/tabela/listabl.asp?c $=1618>$, Acesso em: 25/07/2004.

PANIGRAHI, S. Effects of different copra meals and amino acid supplementation on broiler chick growth. British poultry Science, v.33, p.683-687, 1992.

PHILIP, J.S.; GILBERT, H.J.; SMITHARD, R.R. Growth, viscosity and beta-glucanase activity of intestinal fluid in broiler chickens feed on barley-based diets with or without exogenous betaglucanase. British Poultry Science, v.36, p.599-605, 1995.
PLAVNIK, I. The effect of dietary energy supplied by fat or carbohydrates on broiler chickens and turkey poults.state of Israel/ Ministry of Agriculture and Rural Development Agricultural Research Organization. Shlomo Yahav. Animal Science. Disponível em: $<$ http://www.agri.gov.il/AnimalScience/ Poultry.html>. Acesso em: 16/08/2003.

RODRÍGUEZ-PALENZUELA, P; GARCIA, J.C. de Blas. Fibra soluble y su implicación en nutrición animal: enzimas y probióticos. In: CURSO DE ESPECIALIZACIÓN FUNDACIÓN ESPAÑOLA PARA EL DESARROLLO DE LA NUTRICIÓN ANIMAL, 14., 1998, Barcelona. Anais... Barcelona: FEDNA, 1998. p.229-239.

ROSTAGNO, H.S; ALBINO, L.F.T; DONZELE, J. L. Tabelas brasileiras para aves e suínos: composição de alimentos e exigências nutricionais. Viçosa, MG: Universidade Federal de Viçosa, 2000. 141p.

SCOTT, M.L; NESHEIN, M.C; YOUNG, R.J. Nutrition of the chicken. 2.ed. New York: Ithaca, 1976. 555p.

STATISTICAL ANALYSIS SYSTEM - SAS. System for linear models. Cary: 1986. $211 \mathrm{p}$.

SILVA FILHA, O.L.; OLIVEIRA, R.J.F.; BRAGA, A.P. et al. Efeito da inclusão do pseudofruto do caju sobre o desempenho de frango de corte. IN: REUNIÃO ANUAL DA SOCIEDADE BRASILEIRA DE ZOOTECNIA, 41., 2004. Campo Grande. Anais... Campo Grande: Sociedade Brasileira de Zootecnia, 2004.

TAVARES, V.A. Vagem triturada da algarobeira como ingrediente não ortodoxo de rações para frangos de corte. Recife: Universidade Federal Rural de Pernambuco. 1993. 163p. Dissertação (Mestrado em Produção Animal) - Universidade Federal Rural de Pernambuco, 1993. 